\title{
Instructional Scaffolding, Socioeconomic Status and Oral Performance: A Case of Iranian Preschoolers
}

\author{
Elahe Soleimani \\ Department of English Language, Isfahan (Khorasgan) Branch, Islamic Azad University, Isfahan, Iran \\ e_solimani90@yahoo.com \\ Reza Biria \\ Department of English Language, Isfahan (Khorasgan) Branch, Islamic Azad University, Isfahan, Iran \\ biria_reza@yahoo.com
}

Abstract: This study focused on the analysis of instructional scaffolding and socioeconomic status (SES) on the articulation of English utterances in Iranian preschoolers' English classes. For garnering the relevant corpora, two kindergartens from both High and Low SESs were randomly selected. They were then scrutinized based on preschoolers' portfolio and two classes from each kindergarten were selected as experimental and control groups respectively. During the course of studies, preschoolers in experimental groups were exposed to instructional scaffolding techniques while the presence of such a treatment for control groups was limited to textbook. As such, at the end of the course, preschoolers' English oral performances in each SES strata were compared by administrating only a post-test. The results indicated that scaffolding techniques regardless of their usage in high or low socioeconomic levels had a dramatic effect on preschoolers' performance. All in all, the application of scaffolding tools may pave the way for teachers who are involved in teaching children and also the researchers in such areas.

Keywords: Instructional Scaffolding, Socioeconomic Status, Oral Performance, Iranian Preschoolers, English Utterances.

\section{INTRODUCTION}

Child language acquisition has gained a surprisingly fast momentum in recent years. One of the important issues in this field is the zone of proximal development which is affected by various elements among which instructional scaffolding plays a positive role. Probably one of the primary skills which is noticeable in teaching children is oral proficiency which is of course very limited at the early stages. It is axiomatic that most of the utterances produced by children at the early stages are replete with irrelevant speech. Although the child can understand the tacit concept of interaction, it has trouble using utterances relevantly. Naturally, it is roughly impossible to draw a clear-cut border-line between relevant and irrelevant utterances produced by children in their oral production; however, getting children involved in proficiency-oriented games can guide children to produce more to-the-point utterances on the basis of the materials presented in the process of oral interaction under the supervision of the teacher, who may act as a facilitator to foster scaffolding.

Over the past two decades, there have been numerous investigations into instructional scaffolding; however, the bulk of the research that has been carried out has focused on reading and writing skills. Some studies suggest that the use of instructional scaffolding has a vital impact on the improvement of reading and writing skills in children. This paper mainly focuses on activating the oral production by scaffolding children in terms of relevance maxim. Among three types of scaffolding; namely, vertical, sequential, and instructional, the third one is utilized in this study due to its direct connection with educational settings. Consequently, the present study tries to investigate whether instructional scaffolding can help students to produce more relevant utterances in their interactions and to what extent and how games coupled with graphics can produce a relaxing atmosphere in which a teacher-child interaction or peer-peer interaction may be activated. 
The concept of scaffolding which is attributed to Wood, Bruner and Ross (1976) is defined as, a way in which a skilful expert supports a child toward the solution of a difficult task. This concept is closely in line with Vygotskey's (1978) zone of proximal development. The concept of ZPD revolutionized teaching children and directed the attention of many teachers and researchers to its inherent merits. Many studies considered instructional scaffolding regarding divergent steps which are of high premium concerning scaffolded classes. Most researchers are of the idea that there are two consequential steps regarding instructional scaffolding. The first step refers to the development of some tasks to support learners, and the second step hinges upon putting these tasks into practice which is the same as the universal definition for teaching that refers to putting theory into the practice. As an indispensible factor talking about tasks or plans, demands for special features. For instance, Applebee and Langer (1983) focused on the effectiveness and proper use of the tasks. To be more precise, they highlighted the importance of instructional tasks which result in problems and cannot be solved successfully by the learners themselves. Here, the more able person, that can be the learners' other classmates, teacher, parents, siblings, or friends can support them in completing the tasks above the learners' level of ability.

Evidently, the child's route to autonomy in task completion is affected by numerous elements among which dependence on adults (his or her parents in very early stages and the teacher in the following stages) is very outstanding. Scaffolding and zone of proximal development have been the source of many investigations centering on language learning and teaching. Various definitions of scaffolding and its significance in the genre of language teaching have been presented so far, in most of which the supportive role of scaffolding in language teaching is quite common. As Benson (1997) noted, scaffolding is viewed as an affiliation between what is already known by a child and helping him or her to arrive at what he or she needs to know.

On the other hand, scaffolding is considered as a concept to refer to the supportive role that teachers have in helping children in order to be more independent. Instructional scaffolding and its impact on the process of language learning and task completion has also been the center of attention in various studies which have looked at scaffolding from divergent perspectives (Stone, 1998; Wells, 1999; Hammond, 2002). Larkin (2002) views scaffolding as a useful way of instruction that can meet students' needs. With regard to the vital role of collaboration in language learning, learning may be gained in collaboration between students who have the same level of understanding. Scaffolding support can be analyzed in different ways. However, instructional scaffolding is not perennial, in fact the more proficient students become, the less scaffolding is required (DiazRico \& Weed, 2002). Similarly, Ovando et al. (2003) refer to scaffolding as "providing contextual supports for meaning through the use of simplified language, teacher modeling, visuals and graphics, cooperative learning and hands-on learning".

The presence of scaffolding waxes and wanes regarding the movement of students toward problem solving tasks. Therefore, solving a problem by a child according to what he/she had been taught is a prerequisite for acting collaboratively. Ellis (2008) notes, according to Vygotsky's ZPD that "for interaction to work for acquisition it needs to assist the learner in constructing zone of proximal development and this is achieved with the help of scaffolding". Ellis (2008) asserts that Vygotsky (1978) distinguished 'the actual developmental level that is the level of development of the child's mental functions that has been established as a result of certain already completed developmental cycles' (p. 85).

In addition to the aforementioned levels, Ellis (2008) introduces a third level that lies beyond the learner, he concludes that there are some cases in which even the presence of scaffolding or "assistance" cannot help the learner to complete the task or solve the problem autonomously. This alludes to the fact that coming to terms with a unanimous interpretation of ZPD concept by instructors is out of the question due to the abstract nature 
of ZPD, this means that ZPD can dramatically change from one preschooler to another so much so that a fixed amount of scaffolding can enable a child to solve a problem, whereas the same amount of scaffolding for a peer will not be helpful in solving the same problem. In the same view, Parslow (2009) defines ZPD as the zone in which other skillful peers can facilitate learning process; he also believes that the physical presence of these supporters is not necessary. This idea is closely related to certain studies emphasizing the role of media such as internet in particular, which can serve as an effective tool playing the role of scaffolding in helping children and this support can be in line with the support which is given to children by their instructors or it can be totally different.

Indubitably, the concept of scaffolding is very conducive in language teaching, in particular for preschool teachers. As Pentimonti and Justice (2010) state, a range of scaffolds can be utilized, especially in preschool levels. Williams et al. (2010) suggest that "establishing a positive peer relationship is integral to children's social development and is linked to a variety of long-term outcomes and life skills". Of course the discussion boils down to the fact that many of the activities that are performed by the instructors are not supposed to be considered as a positive support for children; therefore, they should not be classified under the instructional scaffolding category.

A distinction hence should be drawn between a positive support which leads to the completion of tasks by children on the one hand, and giving too much attention to children so that it has a debilitative effect on them, on the other hand. It implies that instructional scaffolding pushes children forward toward autonomous problem solving activities, whereas ample attention of caregivers to children which hinders students' autonomy should not be attributed to scaffolding. Although the concept of scaffolding has gained credence among scholars and researchers in the field of child language acquisition, it still needs to be elucidated because the interpretation of one teacher often varies from others in applying scaffolding in the classroom efficaciously. Thus regardless of the ways scaffolding is applied in educational circumstances, its facilitative function cannot be denied.

Some researchers also suggest that in order to determine the effectiveness of scaffolding in educational settings, it is obligatory to consider the SES of children. In this regard, three indicators distinguish between high and low SESs, namely nutrition, health and education. Different researchers also put emphasize on the relatively positive correlation between nutrition and SES but it is just the tip of the iceberg. Most researchers believe that there is also a positive relation between poor health and children's cognitive ability deficiencies. For instance, Hoff (2003) states that parental SES influence child development to the extent that children from high SES families produce vocabularies with higher rates compared to children from low SES.

The significance of socioeconomic status in educational setting had been started by the work of Coleman et al. (1966) regarding SES in a sundry of educational aspects. Other researchers such as Thomas and Stockton were of the idea that in order to categorize SES in divergent strata, there are some factors including nations, races, places, schools and individuals. In the same vein, Taylor and Yu (2009) stated that although the bulk of research on the significance of SES in education owes much to the contribution of Colman, his investigations did not completely satisfy the expectations of those researchers who are interested in the significance of SES effects on other aspects of students' life.

According to Hart and Risley (1995) as cited in Dieterich et al. (2006), children from low-SES experience a limited utterances and slower rate of speech production in contrast to their counterparts from high-SES who benefit from educated parental environment and upper-class's language styles that is rich and applicable. Therefore scaffolding may result in different performances according to such factors as socioeconomic status (SES). A low or high SES family might affect the language learning. In one study Hart and Risley (1995) showed that children from low SES family have difficulty vocabulary building. Hoff (2003) also believed that high SES children benefit 
more in terms of language learning. In another study Cohen (1999), cited in Bradly and Corwyn (2002), stressed debilitative role of some diseases in childhood and low levels of performance at school. Therefore, most of the researchers such as Bradly and Corwyn (2002), focused on the impact of SES on cognitive abilities of children.

On the other hand, different scholars have attested the necessity of scaffolding in various educational settings. In this regard, McGee and Ukrainetz (2009) delineates the need for intense scaffolding when it comes to teaching phonemes. McGee and Ukrainetz (2009) limned trichotomy in scaffolding phonemic awareness for beginning phonemic isolation. The first category, the intense category, highlights the presence of exaggerated phonemes in isolation and in the word. The second category, moderate category, deals with the moderate level of support in which children are supposed to look at the teacher's mouth while the specific phoneme in the word is exaggerated by the teacher. In the third category of scaffolding which labeled as minima, the initial phoneme in the word is stressed. In conclusion it should be pinpointed that the corollary of their study bears upon the fruitful impacts of scaffolds via instruction with reference to phonemes.

More importantly, Bruner (1983) used the term scaffolding primarily for young learners' oral performance. The concept of instructional scaffolding mostly used in the classroom as an assistant or supportive tool especially during the dialogues that take place in EFL settings. There are many research proposals focusing on speaking and the types of scaffolds in this area but there is a high agreement among researchers about the fact that conversationally oriented strategies result in a better learning. In a study, Meyer and Turner (2002) talk about the importance of assistance and state that in order for a good understanding of the materials there must be collaboration of the shared knowledge among the learners as well as between the learners and the teacher. In the same vein, for their model of teaching and learning, Collins, Brown and Newman (1989) offered useful strategies for those who deal with oral performance problems.

The term 'interactional' scaffolding also introduced to support the idea that the notion of scaffolding, as mentioned by Brush and Saye (2002) no matter how soft or hard it is, scaffolding is a kind of on-the-spot support. It is of a high premium to note that, designed-in or hard scaffolding demands for high levels of support when there is a need for further levels of difficulty (Gibbons, 2002; Hammond, 2001; Brush \& Saye, 2002; Sharp, 2001 as cited in Michell \& Sharp, 2005; see also Rose, Gray \& Cowy, 1999;Van Lier, 1996). There is also a dichotomous relationship between play and oral language abilities. Some researchers believe that play time gives the child an opportunity to improve his or her oral abilities. Children can activate their cognitive knowledge as well as their oral performance during the games. Also in support of the effectiveness of plays for children, it is important to note that Long and Sato (1984) as cited in Tan \& Foley (1994) considered 'conversational' scaffolding as the cornerstone of language learning abilities including styles and strategies.

Since oral performance has a pivotal role in the current research, it should be ascertained that the term oral performance is a moot point when it comes to its clarification. As Iwashita, Prior, Watanabe, and Lee (2010) notes, a clear-cut definition of the term oral performance fluctuates from researcher to researcher. It should also be put that scaffolding divergent classrooms may not be attained simply. In fact, there are some elements at play which debilitate the efficiency of scaffolding. As noted by Kim and Hannafin (2011) the limited background and knowledge of the learners might act as a barrier to learning process and acquisition of knowledge. Likewise, some teachers' predilection to instruct in apropos of scaffolding techniques might be under question.

This study begins with proposing some questions regarding the application of some scaffolding tools for two groups of High and Low SESs in the community of Iran and their possible effect on English oral performance of Iranian young learners at early stages of foreign language development. Therefore based on these research preliminaries and to serve the purpose of the current study, the following research questions and hypotheses were formulated: 


\subsection{Research Questions}

1. Do scaffolded-classes result in a better articulation of English utterances in High-SES Iranian preschoolers' performance?

2. Do scaffolded-classes lead to the better performance in Low-SES Iranian preschoolers' English oral utterances vis-à-vis their High-SES counterparts?

3. Does instructional scaffolding have any relationship with socioeconomic status of Iranian preschoolers in their English oral performance?

\subsection{Research Hypotheses}

In order to answer the aforementioned research questions, the following null hypotheses were formulated:

H1. Scaffolded-classes do not result in a better performance of English utterances in High-SES Iranian preschoolers.

H2. Scaffolded-classes do not lead to a better performance of English utterances in Low-SES Iranian preschoolers' oral performance vis-à-vis their High-SES counterparts.

H3. There is no significant relationship between instructional scaffolding and Iranian preschoolers' SES in the performance of English utterances.

\section{METHOD}

\subsection{Participants}

The participants were taken from two SES levels from two randomly selected kindergartens at Tehran, one from the north of Tehran that mostly high SES level people live there and the other from the south of Tehran. For ascertaining children' SES level several indicators were stressed, such as parental education, occupation, income level and place of residence. Four classes according to preschoolers' portfolio from the two kindergartens were randomly selected.

Table 1.2. Demographic Specification of High-SES preschoolers

\begin{tabular}{|l|l|}
\hline No. of Students & $\mathbf{6 0}$ \\
\hline Gender & Both Male \& Female (39 girls \& 21 boys) \\
\hline Age & $5-7$ Years Old \\
\hline Mother Tongue & Persian \\
\hline Parental Education & B.A, M.A \& Ph.D. \\
\hline Parental Occupation & Professional \& Non-professional \\
\hline Parental Income & Btw. 6,000,000- 9,000,000 Tomans (per month) \\
\hline Place of Residence & Tehran, District 1 or 3 \\
\hline Housing & Both Rental \& Personal Houses \\
\hline Kindergarten & Taban Bilingual Kindergarten, District 3, Africa Highway, Jordan Str. \\
\hline
\end{tabular}


They were then divided into experimental and control groups, 2 classes for each kindergarten. For being on the safe side, the same teacher was chosen for both classes. The students in the control groups attended the class on odd days and their experimental group counterparts attended on even days. The time of class participation for both groups was from 8 A.M. until 9:30 for three days a week.

Preschoolers in the High-SES experimental group were 30 including 18 girls and 12 boys and 23 preschoolers had educated parents with professional positions and salary amount of 6,000,000 to 8,000,000 tomans per month and the other 7 preschoolers had college graduated parents but only 3 of them had parents with professional positions and for 4 of them only fathers had freelance jobs and mothers were housekeeper and also 4 single-parent. The places of residence for 30 High-SES preschoolers in the experimental group were district 1 and 3. In the control group preschoolers were 21 girls and 9 boys, among whom 28 preschoolers had educated families and 4 of them, had parents in freelance jobs with incomes of 6,000,000 to 9,000,000 Tomans per month. Table 3.1 depicts the demographic specification of High-SES preschoolers.

The reason for choosing Tehran among other cities in Iran is that different parts of Tehran ranged by high to low life quality and facilities from north to south and even from east to west. It is interesting to know that such demarcations may have not any logical order in some cases. In Low-SES kindergarten based on preschoolers personal portfolios 2 classes were randomly selected and regarded as experimental and control groups. The preschoolers in Low-SES experimental group were including 17 girls and 13 boys and 11 of them had educated parents with university degrees and their fathers had unskilled jobs with salary amount of 400,000 Tomans to 600,000 Tomans per month. Other 8 preschoolers had school drop-out parents with among which 3 of them were from families with salary amount of 500,000 to 800,000 Tomans salary and lived in rented houses; whereas, for the other 11 preschoolers, parental income was around 600,000 Tomans monthly with school drop-out parents.

The 30 preschoolers in experimental group were including 24 girls and 6 boys and 2 of them were lived in single-parent families. The place of residence for all of them was district 20.The preschoolers in the control group attended the class on even days and the classes were held for experimental group counterparts on odd days. They attended the class from 8 A.M. to 9:30 for three days in a week. Control group Preschoolers were two classes with a total number of 30 that 18 of them were lived in families with salary amount of 500,000 to 700,000 Tomans and 12 of them had unprofessional parental job positions with seasonal salaries around 400,000 to 700,000 Tomans per month. Table 3.2 depicted the demographic characteristics of Low-SES preschoolers.

Table 2.2. Demographic Specification of Low-SES Participants

\begin{tabular}{|l|l|}
\hline No. of Students & 60 \\
\hline Gender & Both Male \& Female (41 girls \& 19 boys) \\
\hline Age & $5-7$ Years Old \\
\hline Mother Tongue & Persian \\
\hline Parental Education & School drop-outs, Diploma \& B.A. \\
\hline Parental Occupation & Non-professional \\
\hline Parental Income & Btw. 400,000- 700,000 tomans (per month) \\
\hline Place of Residence & Tehran, District 20 \\
\hline Housing & Both Rental \& Personal Houses \\
\hline Kindergarten & Jahan Bilingual Kindergarten, District 20, Javanmarde Ghassab Str. \\
\hline
\end{tabular}




\subsection{Materials}

The materials included student's book "Magic Time", its work book and the CD. They were used jointly for both control and experimental groups in both High and Low-SES kindergartens the scaffolding techniques use for experimental groups at two SES levels were including a chant book, "Let's Sing, Let's Chant" and its CD, a puppet, graphic organizers, and also Twister game; whereas, the control groups or non-scaffolded classes were only exposed to textbook. The scaffolding techniques were including modeling the tasks in face-to-face conversations, graphic organizer (visualized images, cue cards, diagrams, posters, etc.), scaffolding-oriented games and a puppet.

\subsection{Data Collection Procedures}

A teacher-made posttest based on Cambridge Young Learners English Test (YLE) starters held at the end of the course. The first 6 units of the Magic Time 1 were taught for 19 sessions. The teacher's syllabus design in control groups was based on the book's manual with totally unconscious and not organized supports. There was no scaffolding technique and no extra tool to be used as supportive during the teaching process. The class activities in the control groups at two SES levels were as follow: First, dialogues act out the by the teachers. Second, dialogues act out by preschoolers after listening to the CD. Third, the use of flash cards related to the lessons. Fourth, the ac of listening to songs related to the book. By contrast, the experimental groups received instructional scaffolding techniques including goal-oriented games that were award free and the games did not have any winners or losers. Other scaffolding techniques were including extra flash cards, puppets for simplifying the tasks by giving clues, graphic organizer, etc.

A typical teaching scenario in experimental groups would be as follows:

T: Can you jump? (Pointing to the selected participant and showing the act of jumping)

S: Yes.

T: Jump on "Dog". (Asking other students that what color is the dog? for giving some clues to the selected student.)

S: [jumps and waits for the teacher's question].

$\mathrm{T}$ : What is it? (Asking question for clarification and better recall)

S: It's a dog. [feels secure and enjoys stress-free learning]

\subsection{Data Analysis Procedures}

Preschoolers' English performance was analyzed based on a modified version of Cambridge Young Learners English Test (YLE) starters (see Appendix A) and both control and experimental groups would be compared based on their test performance in both High and Low-SESs. The test has five parts with four questions in each (see Appendix B). The statistical procedures which were used included three independent sample of t-tests for comparing the experimental and control groups within the High-SES and measuring the scaffolded and non-scaffolded class abilities regarding the significance of SES in High and Low-SESs. Moreover, a two-way ANOVA was used in order to find out interaction between scaffolding and preschoolers' SES. The validity of the instruments in this study was based specialist' opinion. For the reliability of the instruments for measuring the internal consistency the Cronbach's alpha coefficient was used. The obtained correlation coefficient was 0.75.

\section{RESULTS}

In order to investigate the effect of SES on preschoolers' English oral utterances in the modified YLE test and to analyze that to what extent the preschoolers' English performance can be affected by instructional scaffolding 


\section{American Research Journal of English and Literature(ARJEL)}

techniques; the data collected from the two groups was analyzed using independent-sample of t-test for posttest.

\subsection{Hypothesis 1}

Scaffolded-classes do not result in a better performance of English utterances in High-SES Iranian preschoolers.

Table 3.1 depicts the mean score and standard deviation of the preschoolers' English oral performance for the experimental and control groups in High-SES level.

Table 3.1. Descriptive Statistics of Experimental and Control Groups in High-S

\begin{tabular}{|l|c|c|c|}
\hline \multicolumn{1}{|c|}{ Groups } & $\mathbf{n}$ & $\mathbf{M}$ & SD \\
\hline Score Control & 30 & 15.30 & 3.01 \\
Experimental & 30 & 18.46 & 1.56 \\
\hline
\end{tabular}

Table 3.2. Independent-sample of $t$-test of the two groups in High-SES

\begin{tabular}{|c|c|c|c|c|c|}
\hline Source & \multicolumn{2}{|c|}{$\begin{array}{l}\text { Levene's Test For Equality of } \\
\text { Variances }\end{array}$} & \multicolumn{3}{|c|}{$t$-test for Equality of Means } \\
\hline $\begin{array}{l}\text { Equal variances } \\
\text { assumed }\end{array}$ & $\begin{array}{l}\text { F } \\
9.471\end{array}$ & $\begin{array}{l}\text { Sig } \\
.003\end{array}$ & $\begin{array}{l}\mathbf{t} \\
5.09\end{array}$ & $\begin{array}{l}\text { df } \\
58\end{array}$ & $\begin{array}{l}\text { Sig. (2-tailed) } \\
.000\end{array}$ \\
\hline $\begin{array}{l}\text { Equal variances } \\
\text { not assumed }\end{array}$ & & & 5.09 & 43.615 & .000 \\
\hline
\end{tabular}

$\mathrm{P} \geq .05$

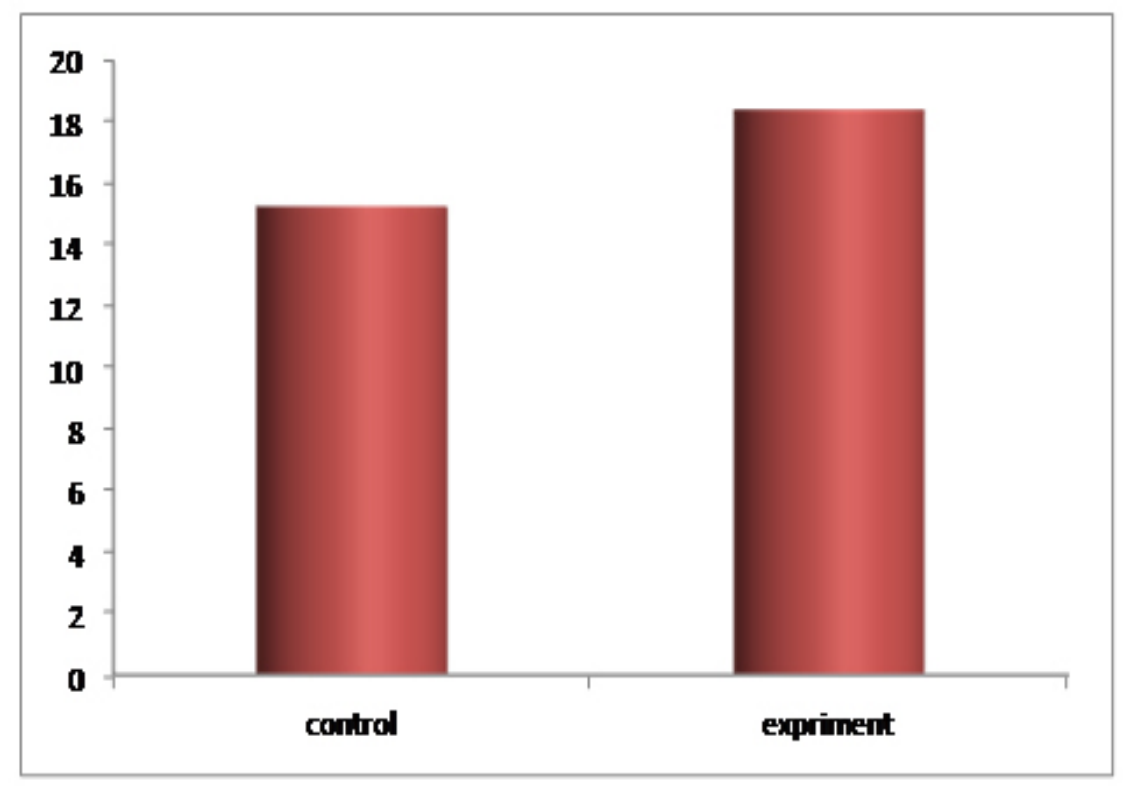

Fig(3.1). Graphical representation of means of two groups in High-SES 
An independent-sample of t-test was used for comparing the High-SES scaffolded-class in experimental group vs. non-scaffolded-class in control group after the posttest, the results revealed that the $\mathrm{p}$ value is less than the critical $\mathrm{p}(.003<.05)$, where the critical $\mathrm{p} \leq .05$ and also the observed $\mathrm{t}(\mathrm{t}=5.09)$ shows that there is a meaningful difference in English performance of experimental group after receiving scaffolding treatment as compared to the English performance of control group. The results of the groups' mean scores and SDs also indicated that there was a significance difference in the mean sore and SD of preschoolers' oral performance after the posttest in control group $(M=15.30, S D=3.01)$ as compared with the mean sore and $S D$ of the posttest of experimental group $(M=18.46, S D=1.56)$ shows that instructional scaffolding techniques had a dramatically meaningful effect on the performance of preschoolers in experimental group in High-SES level. Evidently, by illustrating the mean differences of the two groups in High-SES level it is obvious that preschoolers in experimental group outperformed their control group counterparts as shown in Figure 3.1.

\subsection{Hypothesis 2}

Scaffolded-classes do not lead to a better performance of English utterances in Low-SES Iranian preschoolers' oral performance vis-à-vis their High-SES counterparts.

In order to describe the significance of instructional scaffolding techniques in Low-SES and to synthesis the discrepancies between scaffolded and non-scaffolded groups in Low-SES, preschooler's English oral performance was analyzed by independent sample of t-test after administrating the posttest. Table 3.3 depicts the mean score and standard deviation of the two groups in Low-SES level after the posttest.

Table3.3. Descriptive Statistics for Control and Experimental Groups in Low-SES

\begin{tabular}{|c|c|c|c|}
\hline Groups & n & M & SD \\
\hline Score Control & 30 & 13.93 & 3.57 \\
Experimental & 30 & 17.63 & 2.23 \\
\hline
\end{tabular}

Table3.4. Independent-sample of t-tests of the two groups in Low-SES level

\begin{tabular}{|l|ll|l|l|l|}
\hline Source & \multicolumn{3}{l|}{$\begin{array}{l}\text { Levene's Test for } \\
\text { Equality of Variances }\end{array}$} & \multicolumn{3}{l|}{$t$ t-test for Equality of Means } \\
\hline $\begin{array}{l}\text { Equal variances } \\
\text { assumed }\end{array}$ & $\mathbf{F}$ & $\mathbf{S i g}$ & $\mathbf{t}$ & $\mathbf{d f}$ & Sig. (2-tailed) \\
$\begin{array}{l}\text { Equal variances } \\
\text { not assumed }\end{array}$ & 6.257 & .015 & 4.81 & 58 & .000 \\
\hline
\end{tabular}

$\mathrm{P} \geq .05$

As Table 3.4 revealed the $\mathrm{p}$ value is less than the critical $\mathrm{p}(.015<.05)$, where the critical $\mathrm{p} \leq .05$ and also the observed $\mathrm{t}(\mathrm{t}=4.81)$ reveals that preschoolers' English oral performance was meaningfully different in experimental group which means that scaffolding strategies had statistically outstanding impact on their oral performance. Moreover, by comparing the mean score and SD of preschoolers' performance after the posttest at two groups in Low-SES level, the results shows that the mean and SD of the control group's posttest $(M=13.93$, $\mathrm{SD}=3.57)$ in comparison with the performance of their counterparts in experimental group $(M=17.63, \mathrm{SD}=2.23)$ is significantly different. The difference between the two groups in Low-SES level shows the effectiveness of scaffolding tools in experimental group. Figure 3.2 illustrated the mean differences after administrating the posttest for both groups and the outperformance of scaffolded-classroom in Low-SES level. 


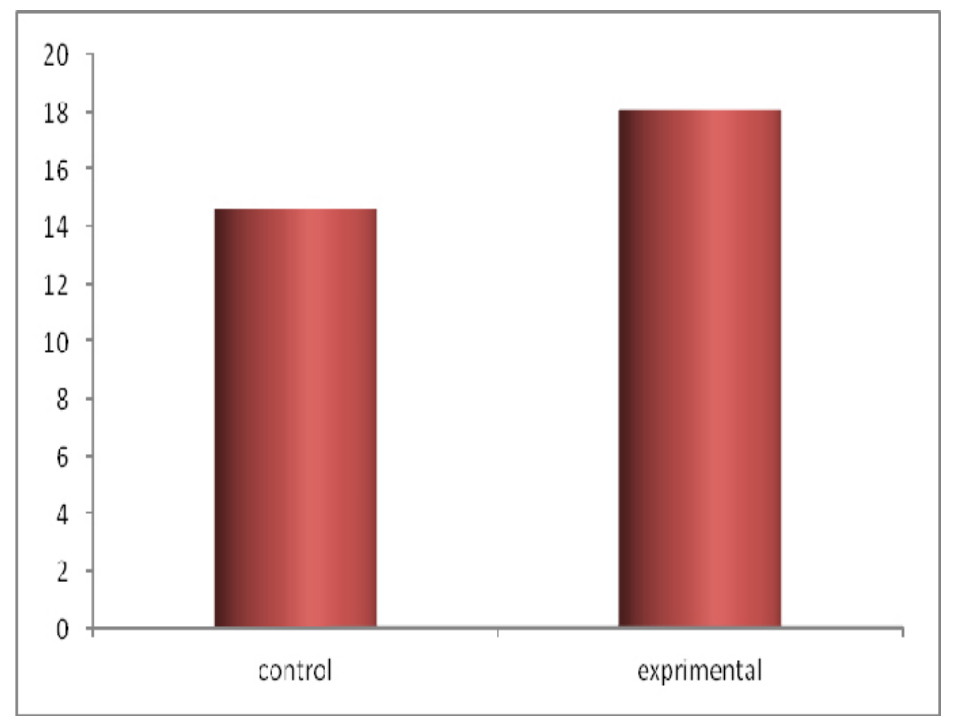

Fig(3.2). Graphical representation of means of two groups in Low-SES

In order to compare the impact of scaffolding techniques in High and Low-SESs and to see which level of SES benefited more from scaffolded-classes, the mean score and SD of two experimental groups at two SES levels were compared. Table 4.5 depicted the mean differences between the Low-SES scaffolded-class vs. its High-SES counterpart after administrating the posttest. As it is shown in the table the mean score of HighSES experimental group ( $M=18.46, S D=1.56)$ is slightly higher than the mean score of Low-SES experimental group $(M=17.63, S D=2.23)$ which means that scaffolding techniques had almost the same impact on English performance of preschoolers at two SES levels.

Table3.5. Descriptive Statistics of mean differences of two Experimental Groups in two SES levels

\begin{tabular}{|l|l|l|l|l|}
\hline & Groups & $\mathbf{n}$ & $\mathbf{M}$ & SD \\
\hline \multirow{3}{*}{ Score } & Low-SES & 30 & 17.63 & \\
& High-SES & 30 & 18.46 & 2.23 \\
& & & 1.56 \\
\hline
\end{tabular}

Table3.6. Independent-sample of t-test for Experimental groups at two SES levels

\begin{tabular}{|l|ll|l|l|l|}
\hline Source & \multicolumn{2}{|l|}{$\begin{array}{l}\text { Levene's Test for } \\
\text { Equality of Variances }\end{array}$} & \multicolumn{3}{|l|}{$t$-test for Equality of Means } \\
\hline $\begin{array}{l}\text { Equal variances } \\
\text { assumed }\end{array}$ & $\mathbf{F}$ & Sig & $\mathbf{t}$ & $\mathbf{d f}$ & \multicolumn{1}{l|}{ Sig. (2-tailed) } \\
$\begin{array}{l}\text { Equal variances } \\
\text { not assumed }\end{array}$ & 4.825 & .032 & -1.67 & 58 & .100 \\
\hline
\end{tabular}

$\mathrm{P} \geq .05$

As independent-sample of t-test revealed the result of the performance in scaffolded-classes at two SES levels, the $\mathrm{p}$ value is less than the critical $\mathrm{p}(.032<.05)$, which shows that the two groups at two SES strata were not dramatically different in their posttest after receiving the scaffolding treatment. The results of the independent- 
sample of $\mathrm{t}$-test also shows that the observed $\mathrm{t}(\mathrm{t}=1.67)$ indicates no meaningful difference between the performance of two experimental groups at two SES levels. Figure 3.3 also represents the mean differences in two experimental groups at two SES strata and the insignificance of differences between the performances of the said groups.

\subsection{Hypothesis 3}

There is no significant relationship between instructional scaffolding and Iranian preschoolers' SES in the performance of English utterances.

To measure the amount of relationship between scaffolding techniques used in the two experimental groups and preschoolers' SES, their English oral performance at experimental and control groups at two SES levels were compared and the mean scores of between the groups differences were tabulated in Table 3.7 among 60 preschoolers where the Low-SES scaffolded and non-sclaffolded means $(M=15.78, S D=3.49)$ in comparison with their High-SES counterparts with the mean score of $(M=16.33, S D=3.23)$ revealed their posttests' English oral performance. The table revealed the slight mean differences between the groups which indicate the partial effect between two groups and two SES levels. This shows that scaffolding techniques regardless of preschoolers' SES level had almost the same results in their English oral performance.

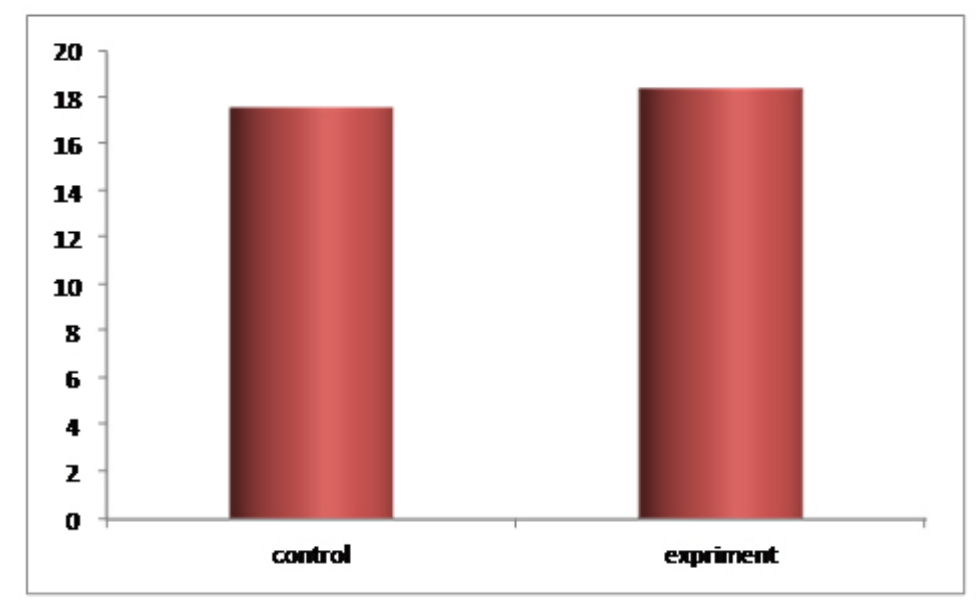

Fig(3.3). Graphical representation of means of Experimental groups at two SES levels

Table3.7. Between the groups mean differences

\begin{tabular}{|l|c|c|}
\hline Between groups comparisons & Mean difference & Sig. \\
\hline HSCG vs. HSEG & -3.16 & .003 \\
LSCG vs. LSEG & -3.70 & .015 \\
HSEG vs. LSEG & -.83 & .032 \\
\hline
\end{tabular}

$\mathrm{p}>.05$

As it can be seen by comparing the mean difference of High-SES Control Group (HSCG) with High-SES Experimental Group (HSEG), also Low-SES Control Group (LSCG) vs. Low-SES Experimental Group (LSEG), one could come to the conclusion that the mean differences between the groups is significance because the $\mathrm{P}$ value $(\mathrm{p}=.003)$ for the High-SES group when the critical $\mathrm{p}$ is $(\mathrm{p}>.05)$, and the P value ( $\mathrm{p}=.015)$ for the Low-SES group when the critical $p$ is $(p>.05)$ are meaningful. Moreover, by comparing High-SES Experimental Group (HSEG) and Low-SES Experimental Group (LSEG), the mean difference $(M=-.83$ ) is not meaningful which shows no 
significant relation between SES level and preschoolers' English oral performances.

Table3.8. Tests of Between-Subjects Effects

\begin{tabular}{|l|c|l|l|l|l|}
\hline Source & $\begin{array}{c}\text { Type III } \\
\text { Sum of Squares }\end{array}$ & df & MS & F & Sig \\
\hline Corrected model & 392.067 & 3 & 130.68 & 17.82 & .000 \\
\hline Intercept & 32013.333 & 1 & 32013.33 & 4365.79 & .000 \\
\hline SES & 36.300 & 1 & 36.30 & 4.95 & .028 \\
\hline Group & 353.633 & 1 & 353.53 & 48.22 & .000 \\
\hline SES * Group & 2.133 & 1 & 2.13 & .291 & .591 \\
\hline Error & 850.600 & 116 & 7.33 & & \\
\hline Total & 33256.000 & 120 & & & \\
\hline Corrected total & 1242.667 & 119 & & & \\
\hline
\end{tabular}

Accordingly, the result of the two-way ANOVA shows no meaningful relationship between scaffolding and Iranian preschoolers' SES level in their English oral performance. Therefore, to measure the strength of association of the data and demonstrating the ratio of variability in the dependent variable the eta squared was run. According to table 3.9 the $\eta 2=.003$ which does not reveals a strong relationship between the dependent and independent variables.

Table3.9. Measures of Association of the Two-way ANOVA

\begin{tabular}{|l|c|c|c|c|}
\hline & $\mathbf{R}$ & $\mathbf{R 2}$ & Eta & $\eta \mathbf{2}$ \\
\hline Scores $・$ Groups & .298 & .316 & .294 & .003 \\
\hline
\end{tabular}

Table3.10. Two-way ANOVA for YLE-test Scores on the Post-test

\begin{tabular}{|l|c|c|c|c|c|}
\hline \multicolumn{1}{|c|}{ Source } & df & SS & MS & F & Sig. \\
\hline Between groups & 3 & 392.67 & 130.68 & 17.82 & .000 \\
Within groups & 116 & 850.60 & 7.33 & & \\
Total & 119 & & & & \\
\hline
\end{tabular}

$\mathrm{p}<.05$

The results of a two-way ANOVA indicated that there is no statistically meaningful difference between the groups, $(\mathrm{F}=.291, \mathrm{p}=.591)$, where the $\mathrm{p}$ value is more than the critical $\mathrm{p}(.591>.05)$. On the other hand, the differences between two levels is significant $(F=4.95, p=.028)$ and the $p$ value is less than the critical $p(.028<$ $.05)$ which indicates the difference between the performance of High-SES preschoolers vis-à-vis their Low-SES counterparts after scaffolding techniques treatments.

Also as the estimated marginal means of scores represented in Figure 3.4 the mean scores of the High-SES (M= 18.46) and Low-SES group ( $M=17.63)$ in experimental groups as compared with the mean score of HighSES $(M=15.30)$ and Low-SES group $(M=13.93)$ in control groups, shows the insignificant difference in both experimental groups at two SES levels and the dramatic difference of the two control groups at two SES levels. 


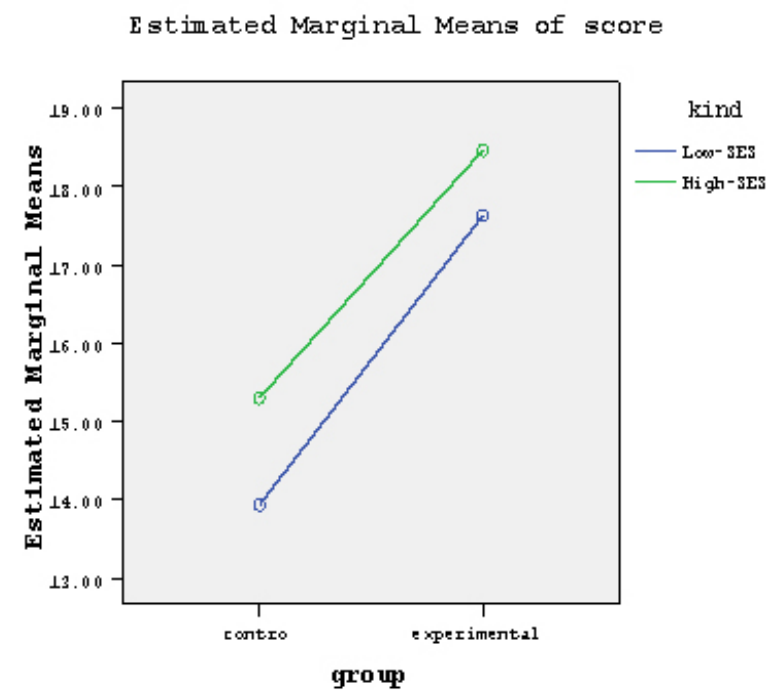

Fig.(3.4). Comparison of mean scores in experimental/control groups in High/Low SESS

\section{Discussion AND CONCLUSION}

In order to investigate the interaction between instructional scaffolding and SES in Iranian preschoolers' English oral performance, three research questions were proposed and three hypotheses were formulated based on them. The three hypotheses were analyzed in the results by administrating a posttest based on YLE and measuring the mean scores, SDs, and independent sample t-test test and by comparing groups' performances in each socioeconomic level.

\subsection{Research Question One}

Do scaffolded-classes result in a better articulation of English utterances in High-SES Iranian preschoolers' performance?

The results indicated that scaffolding techniques could result in a better performance of Iranian preschoolers in High-SES level. Therefore the first hypothesis is rejected. As the result of testing the first hypothesis reveals, High-SES learners at experimental group outperformed their control group counterparts. As Hoff (2003) stated that High-SES children have a greater vocabularies collection. Furthermore, the result supports the fact of parental High-SES and children's academic achievements and success during the classrooms. Also in another study as Hart and Risley (1995) argued there is positive relation between having High-SES families and children's academic and cognitive growth.

\subsection{Research Question Two}

Do scaffolded-classes lead to the better performance in Low-SES Iranian preschoolers' English oral utterances vis-à-vis their High-SES counterparts?

The second research question refers to the significance of instructional scaffolding in Low-SES preschoolers' English oral performance. The results of testing the second hypothesis indicated that Low-SES preschoolers 
that were exposed to scaffolding techniques in experimental group performed dramatically better than their control group counterparts, so that the first part of the second hypothesis is rejected. More importantly, for the second part of this hypothesis that is a comparison between two experimental groups at two SES levels, the findings indicated that there was no significant difference between the English oral performances of High-SES vs. Low-SES preschoolers' performances in their posttest after receiving scaffolding techniques which means that the educational facilities regardless of children's SES level, leads to advancements in cognitive and academic abilities of the learners. The gained results are in commensurate with what Bradly and Corwyn (2002) stated that the environment and academic settings are crucial for academic and cognitive development.

\subsection{Research Question Three}

Does instructional scaffolding have any relationship with socioeconomic status of Iranian preschoolers in their English oral performance?

The third research question is related to the possible relation between instructional scaffolding and the socioeconomic level of Iranian preschoolers' English oral performances. After testing hypothesis three the result indicated that there is no dramatically significant relationship between instructional scaffolding and SES level in Iranian preschoolers' English oral performances. The performance of the two experimental groups at two levels and the insignificant differences between the mean score of these two groups also between the groups' differences indicated the ignorable meaningful relation between instructional scaffolding on the one

hand and socioeconomic status on the other hand. These findings are in line with Larkin (2002) ideas about the accurate application of scaffolding tools to the needs of the preschoolers.

\section{CONCLUSION}

In conclusion, one could say the techniques used as scaffolding during the teaching process result in collaborative learning environment in which both teachers and learners can benefit more from the positive effect of more knowledgeable others to support them and make them feel secure during the teaching phase. The aforementioned findings are in agreement with Williams et al. (2010). They also believe that peer-peer interaction in developing social connection networks plays a crucial role in increasing cognitive skills and strategies. In the final run, the scaffolded learners may learn better in more determined steps compared to non-scaffolded learners. The findings may also have theoretical and pedagogical implications for the researches, policy makers, educational systems, and more importantly for the teachers and learners especially for preschoolers that because of the shortage a good teaching method in this area most of the teachers expect their young learners to act and learn in the same way that adults do.

As such policy makers can think of learners' needs and also the advantage of stress-free classes that let the learners to work on their abilities better and enjoy supporting each other while they find a problem cumbersome or dissolvable. Considering the limitations of the study, one might think of the application of such techniques in different cultures and analyze the cultural differences in terms of driving such support or even accepting these kinds of supports. One may wish to duplicate this study for students with different age ranges or proficiency levels. In addition, one can do the same research with other types of scaffolding strategies. One also might run the research for learners with learning disabilities to garner more corpora about children with special diseases and their process of language learning.

The study also has some implications for further research regarding the application of instructional scaffolding in other societies that are subject to the presence of different socioeconomic strata in their educational settings. The difference between High-SES and Low-SES leads to a sundry of tribulations when it comes to teaching and learning. Many researchers have asserted that students from High-SES have gained more academic 
accomplishments in comparison to their Low-SES counterparts. However, the presence of some scaffolding tools for the Low-SES learners in every place around the world may result in better social and cognitive abilities. For instance some researchers have stressed the consequential impact of students' SES on their educational success. In this regard, Hoff (2003) has stated that parental and family-bound SESs can have a dramatically significant bearing upon children's pedagogical gains in their future successes. The ideas are also in line with Kim and Hannafin (2011) regarding the effectiveness of scaffolding techniques for the removal of cognitive barriers.

As the purpose of the current study was based on the effectiveness of some instructional techniques such as games, plays, and supports, the results was a testimony to the conviction that such supports can decrease the cognitive differences derived from learners' divergent SESs. Therefore one could possibly say that cognitive abilities which owe much to the learners' High and Low-SESs can be improved in academic settings by dint of such supports. The concept of oral performance in this study is limited to the correct articulation of some simple English utterances by Iranian preschoolers. Moreover, it should be mentioned that oral performance can range from the articulation of phonemes to the complete production of complicated sentences, paragraphs and long texts. Therefore, the current study is in line with what Iwashita et al. (2010) stated considering the concept of oral performance and its possible levels in divergent educational settings. There are also some implications for teachers in the realm of oral performance of the learners and the finding may have positive impacts on the performance of teachers who work with preschoolers and deal with teaching foreign languages.

In the final remarks, it should be reiterated that there are some limitations for the present study. The first limitation stems from the application of such scaffolding tools for the oral performance of Iranian preschoolers; however, the usefulness of supportive techniques in other fields of learning a foreign language including preschoolers' reading and writing may be subject to further investigations. Also it is worth noting that these scaffolding techniques can be supportive for other groups of learners including teenagers, adults, and university students and in other places in Iran. Therefore, some other factors beside SES of the learners may affect their learning of new materials, especially when it comes to teaching and learning in an EFL context. These factors can range from learners' age, background knowledge, cultural differences, motivation and learning styles and strategies to their learning (dis)abilities, problems and opportunities and more importantly the decisions made by the policy makers and other stake holders in the realm of language learning and teaching for their educational objectives.

\section{REFERENCES}

1. Applebee, A. N., \& Langer, J. A. (1983). Instructional scaffolding: Reading and writing as natural language activities. Language arts, 60: 168-175.

2. Benson, B. (1997). Scaffolding (Coming to Terms). English Journal, 86(7), 126-127.

3. Bradley, R. H., \& Corwyn, R. F. (2002). Socioeconomic status and child development. Annual review of psychology, 53(1), 371-399.

4. Bruner, J. S. (1983). Child's talk: Learning to use language. New York: W.W. Norton.

5. Brush T. A. \& Saye J. W. (2002). A Summary of Research Exploring Hard and Soft Scaffolding for Teachers and Students Using a Multimedia Supported Learning Environment. The Journal of Interactive Online Learning, 1(2), Fall 2002.

6. Cohen, S. (1999). Social status and susceptibility to respiratory infections. See Adler et al. 1999, pp. 246-53. 
7. Coleman, J. S., Campbell, E., Hobson, C., McPartland, J., Mood, A., Weinfeld, F., \& York, R. (1966). Equality of educational opportunity. Washington, DC: U.S. Government Printing Office.

8. Collins, A., Brown, J. S., \& Newman, S. E. (1989). Cognitive apprenticeship: Teaching the crafts of reading, writing, and mathematics. In L. B. Resnick (Ed.), Knowing, learning, and instruction: Essays in honor of Robert Glaser (pp. 453-494). Hillsdale, NJ: Lawrence Erlbaum Associates, Inc.

9. Diaz-Rico, L.T., \& Weed, K. Z. (2002). The cross-cultural, language, and academic development handbook: A complete K-12 reference guide (2nd ed.). Boston: Ally \& Bacon.

10. Dieterich S.E., Assel M. A., Swank P., Smith K. E. \& Landry S. H. (2006) The impact of early maternal verbal scaffolding and child language abilities on later decoding and reading comprehension skills. Journal of School Psychology 43 (2006) 481-494.

11. Ellis, R. (2008). The study of second language acquisition. Oxford: Oxford University Press.

12. Hammond, J. (Ed.) (2002) Scaffolding Teaching and Learning in Language and Literacy Education. Newtown, Australia: PETA.

13. Gibbons, P. (2002). Scaffolding language scaffolding learning: Teaching second language learners in the mainstream. Portsmouth, NH: Heinemann.

14. Hammond, J. (Ed.). (2002). Scaffolding teaching and learning in language and literacy education. Newtown, Australia: PETA.

15. Hammond, J. (2001). Scaffolding and language. In J. Hammond (Ed.), Scaffolding: Teaching and learning in language and literacy education (pp. 15-30). Newtown, NSW: PETA.

16. Hart B., \& Risley, T. (1995). Meaningful differences. Baltimore: Brookes. Co.

17. Hoff, E. (2003). Causes and consequences of SES-related differences in parent-to-child speech. In M. H. Bornstein (Ed.), Socioeconomic status, parenting, and child development (pp. 147-160). Mahwah, NJ: Erlbaum.

18. Iwashita, N., Prior, M. T., Watanabe, Y., \& Lee, S. K. (2010). Features of oral proficiency in task performance by EFL and JFL learners. In Selected proceedings of the 2008 second language research forum (pp. 32-47).

19. Kim, M. C., \& Hannafin, M. J. (2011). Scaffolding problem solving in technology-enhanced learning environments (TELEs): Bridging research and theory with practice. Computers \& Education, 56(2), 403-417.

20. Larkin, M. (2002). Using scaffolded instruction to optimize learning. Arlington, VA: ERIC Clearinghouse on Disabilities and Gifted Education. (Retrieved September 25, 2007 from ERIC at EBSCOhost, ERIC No. ED. 474 301).

21. Long, M. \& Sato, C. (1984). 'Methodological issues in interlanguage studies: an interactionist perspective' in A. Davies, C. Criper and A. Howatt (eds.) Interlanguage. Edinburgh: Edinburgh University Press.

22. Meyer, D., \& Turner, J. (2002). Using instructional discourse analysis to study the scaffolding of self-regulation. Educational Psychologist, 37(1), 17-25.

23. McGee, L. M., \& Ukrainetz, T. A. (2009). Using scaffolding to teach phonemic awareness in preschool and kindergarten. The Reading Teacher,62(7), 599-603.

24. Michell M. \& Sharpe T. (2005), Collective instructional scaffolding in English as a Second Language classrooms, Prospect Vol. 20, No. 1 April 2005. 
25. Ovando, C., Collier, V., \& Combs, M. (2003). Bilingual and ESL classrooms: Teaching multicultural contexts (3rd ed.). Boston: McGraw-Hill.

26. Parslow, P. (2009). Vygotsky, ZPD, Scaffolding, Connectivism and Personal Learning Networks. Retrieved from http://brains.parslow.net/trackback/1558.

27. Pentimonti, J. M. and Justice, L.M. 2010).Teachers' use of scaffolding strategies during read alouds in the pre-school classroom.Early Childhood Education Journal, 37(4) 241-248.

28. Rose, D., Gray, B., \& Cowey, W. (1999). Scaffolding reading and writing for Indigenous children in school. In P. Wignall (Ed.), Double power: English literacy in Indigenous schooling. Melbourne: Language Australia.

29. Sharpe, T. (2001). Scaffolding in action: Snapshots from the classroom. In J. Hammond (Ed.), Scaffolding: Teaching and learning in language and literacy education (pp. 31-48). Newtown, NSW: PETA.

30. Stone, C. A. (1993). What is Missing in the Metaphor of Scaffolding? Chapter 6 in C.A. Stone, N. Minick \& E. A. Forman (Eds.), Context for Learning: Sosiocultural Dynamics in Children's Development, pp. 169 - 183. NewYork: University Press.

31. Tan, P. \& Foley, J., (1994). Key concepts in ELT. ELT Journal Volume 48/1 January 1994 Oxford University Press 1994 Retrieved from http://eltj.oxfordjournals.org. August 1993.

32. Van Lier, L. (1996). Interaction in the language classroom: Awareness, autonomy and authenticity. London: Longrnan.

33. Vygotsky, L.S. (1978). Mind in society: The development of higher psychological processes (M. Cole, V. John-Steiner, S. Scribner, \& E. Souberman, Eds. \& Trans.). Cambridge, MA: Harvard University Press. (Original work published 1934)

34. Wells, G. (1999). Dialogic Inquiry: Towards a Sociocultural Practice and Theory of Education. New York: Cambridge University Press.

35. Williams, S. T, Mastrgeorge, A. M, \& Ontai, L. L. (2010). Caregiver Involvement in Infant Peer Interactions: Scaffolding in Social content. Early Childhood Research Quarterly. vol.25, issue2, p.p. 255-266.

36. Wood, D., Bruner, J., \& Ross, G. (1976). The role of tutoring in problem solving. Journal of Child Psychology and Psychiatry, 17, 89-100.

37. Yu, F. Y. (2009). Scaffolding student-generated questions: Design and development of a customizable online learning system. Computers in Human Behavior, 25(5), 1129-1138.

Citation: Elahe Soleimani, Reza Biria Department of English Language, Isfahan (Khorasgan) Branch, Islamic Azad University, Isfahan, Iran. Instructional Scaffolding, Socioeconomic Status and Oral Performance: A Case of Iranian Preschoolers American ReserachJournal of English and Literature Volume 3, 2017; pp:1-17

Copyright (C) 2017 Elahe Soleimani, Reza Biria This is an open access article distributed under the Creative Commons Attribution License, which permits unrestricted use, distribution, and reproduction in any medium, provided the original work is properly cited. 